\title{
Bartonelose: análise molecular e sorológica em gatos do Rio de Janeiro - Brasil
}

\section{Bartonellosis: molecular and serological analysis in cats from Rio de Janeiro - Brazil}

\begin{abstract}
Aline Moreira de Souza, ${ }^{*}$ Daniele Nunes Peixoto de Almeida, ${ }^{* *}$ Alexsandro Guterres, ${ }^{* *}$ Rafael Gomes, ${ }^{* *}$ Alexsandra Rodrigues de Mendonça Favacho, ${ }^{* *}$ Namir dos Santos Moreira, ${ }^{* * *}$ Letícia Mendes Puppio Maia, ${ }^{* * *}$ Tatiana Rozental, ${ }^{* *}$ Rodolpho de Almeida Torres Filho, ${ }^{* * * *}$ Aloysio de Mello Figueiredo Cerqueira, ${ }^{* * * *}$ Elba Regina Sampaio de Lemos, ${ }^{* *}$ Nádia Regina Pereira Almosny*
\end{abstract}

\begin{abstract}
Resumo
Bartonella henselae e mais recentemente $B$. quintana têm sido apontados como agentes causais de diversas moléstias em humanos, entre as quais a doença da arranhadura do gato, endocardite, meningoencefalite e neuroretinite, podendo levar ao óbito, principalmente os imunocomprometidos. O gato doméstico é considerado o principal animal envolvido na transmissão destes patógenos. Constituiu-se objetivo deste estudo a avaliação da frequência de Bartonella spp. em gatos domésticos domiciliados do município de Vassouras (RJ) comparando-se os achados na reação em cadeia pela polimerase (PCR) e na sorologia por imunofluorescência indireta (IFA). Amostras sanguíneas de 37 (100\%) gatos de um abrigo da cidade de Vassouras (RJ) foram analisadas, sendo $36(97,3 \%)$ positivas na PCR para Bartonella spp. Das amostras PCR positivas, nove $(25 \%)$ e $27(75 \%)$ apresentaram, respectivamente, reatividade e ausência de reatividade ao IFA. Apenas uma $(2,7 \%)$ amostra de sangue foi concomitantemente negativa na PCR e IFA para Bartonella spp. Este é o primeiro registro de infecção por Bartonella spp. em felinos domésticos no estado do Rio de Janeiro (Brasil) identificada por análise molecular e sorológica, o que nos permite concluir que este agente zoonótico está presente em alta frequência em gatos domésticos do município de Vassouras (RJ).
\end{abstract}

Palavras-chave: bartonelose, frequência, felinos.

\begin{abstract}
Bartonella henselae and B. quintana have been pointed as causal agents of many diseases in humans, and can lead to death, mainly immunodefficient people. Domestic cat is considered the unique animal in transmission of these pathogens. The purpose of this study was to evaluate the frequency of Bartonella spp. in domestic cats from Vassouras city (RJ) by polimerase chain reaction (PCR) and indirect immunofluorescence test assay (IFA) and compare the results. Blood samples from $37(100 \%)$ domestic cats from a shelter of Vassouras city (RJ) were analyzed and $36(97.3 \%)$ were considered positive by polymerase chain reaction (PCR). The indirect immunofluorescence test assay (IFA) revealed $9(25.0 \%)$ and $27(75.0 \%)$ of that PCR positive samples showed, respectively, reaction and absence of reaction to IFA. Only one sample (2.7\%) was negative in PCR and IFA. This is the first communication of Bartonella spp. infection in domestic cats in Rio de Janeiro State (Brazil) identified by molecular and serological assays, thus it can be concluded that this zoonotic agent is present in high frequencies in domestic cats from Vassouras city (RJ).
\end{abstract}

Keywords: bartonellosis, frequency, feline.

\section{Introdução}

Membros do gênero Bartonella são organismos do subgrupo alfa-2 da classe das Proteobacterias, família Bartonellaceae, cujo cultivo é extremamente complexo (Breitschwerdt e
Kordick, 2000; Fenollar e Raoult, 2004; Wikswo et al., 2007). A maioria destas bactérias são bacilos que se aderem a eritrócitos ou células endoteliais (Breitschwerdt e Kordick, 2000). Mais de 23 espécies e subespécies são reconhecidas neste gênero até o momento, sendo que a maioria foi

\footnotetext{
Departamento de Patologia e Clínica Veterinária - Faculdade de Veterinária - Universidade Federal Fluminense. Rua Vital Brazil Filho, 64. Niterói, RJ. CEP 24230-340.

** Laboratório de Hantaviroses e Rickettsioses - Instituto Oswaldo Cruz/FIOCRUZ

*** Programa de Pós-Graduação em Medicina Veterinária - Clínica e Reprodução Animal - Universidade Federal Fluminense.

**** Departamento de Zootecnia - Faculdade de Veterinária - Universidade Federal Fluminense.

*****Departamento de Microbiologia - Instituto Biomédico - Universidade Federal Fluminense.

A quem enviar a correspondência: Aline Moreira de Souza - alinemoreiras@gmail.com
} 
reclassificada recentemente (Brenner et al., 1993), saindo dos gêneros Rochalimea e Granhamella. Entre elas, $B$. bacilliformis, $B$. quintana, $B$. vinsonii subsp. berkhoffii, $B$. henselae, B. elizabethae, B. grahamii, B. washoensis, $B$. koehlerae, $B$. clarridgeiae, $B$. rochalimae e $B$. tamiae são apontadas como agentes causais de moléstias em seres humanos (Chomel et al., 2006 ; Lamas et al., 2008a; Breitschwerdt, 2008; Mogollon-Pasapera, 2009).

Infecções por Bartonella spp. em humanos podem determinar inúmeras moléstias, entre as quais doença da arranhadura do gato (DAG), endocardite, encefalopatia e meningite asséptica. Bartonella henselae é o principal agente causal, mas $B$. quintana também tem sido apontada com frequência como agente causal destas moléstias em humanos. Algumas destas doenças podem ser letais, principalmente em pacientes imunocomprometidos (Chomel et al., 2006; Lamas et al., 2008a; Mogollon-Pasapera, 2009).

Felinos domésticos e selvagens são considerados o principal reservatório de $B$. henselae, $B$. koehlerae e $B$. clarridgeiae por vários autores (Kordick et al., 1999; Breitschwerdt e Kordick, 2000; Lamas et al., 2008 a; Breitschwerdt, 2008; Mogollon-Pasapera, 2009), sendo ainda apontados como reservatório potencial de $B$. quintana (Breitschwerdt et al., 2007).

A transmissão de $B$. henselae ocorre através de arranhadura, mordedura ou contato com a saliva do gato doméstico portador. Pulgas da espécie Ctenocephalides felis são descritas como vetores naturais, pois, quando infectadas, eliminam a bactéria viável nas fezes, que contaminarão as patas e dentes do felino, possibilitando a transmissão (Breitschwerdt e Kordick, 2000; Zanutto et al., 2001; Lappin et al., 2006). No entanto, comprovando a complexidade da sua manutenção na natureza, o material genético de Bartonella spp. também já foi isolado de carrapatos de vários gêneros (Wikswo et al., 2007; Mogollon-Pasapera, 2009).

A bacteremia em gatos domésticos infectados pode ocorrer por um período variável ou ser intermitente. Gatos portadores apresentam-se assintomáticos ou com poucos sinais clínicos. Experimentalmente, febre, letargia, anorexia, linfadenopatia regional e miocardite, entre outras, já foram observados e a gravidade dos sinais clínicos foi determinada pela cepa de $B$. henselae inoculada (Zanutto et al., 2001; FÉRRES et al., 2005; BREITSCHWERDT, 2008).

O diagnóstico de infecção por Bartonella spp. pode ser realizado através de cultura, microscopia eletrônica, teste sorológico e molecular. O diagnóstico através de cultura é laborioso e pode demorar de uma semana a 56 dias, além de requerer condições adequadas de biossegurança, o que dificulta a sua utilização na prática clínica. (Breitschwerdt e Kordick, 2000; Zanutto et al., 2001; Fenollar e Raoult, 2004). Quanto aos testes sorológicos, a IFA é o método mais frequentemente utilizado e, assim como o ensaio imunoenzimático (ELISA), se encontra comercialmente disponível, embora não seja possível através desta técnica discriminar a espécie de Bartonella que causou a infecção (Zanutto et al., 2001). A reação em cadeia pela polimerase (PCR) permite 0 diagnóstico rápido e seguro de infecções causadas por organismos para os quais a cultura pode ser extremamente difícil, como é o caso da Bartonella spp., além de permitir a diferenciação entre as espécies (Fenollar e Raoult, 2004).
Nos últimos 20 anos, estudos sobre a prevalência de Bartonella spp. em humanos, felinos e outras espécies animais têm aumentado em diferentes regiões do mundo (Case et al., 2006; Lappin et al., 2006; Solano-Gallego et al., 2006; Diniz et al., 2007; Lamas et al., 2008 a). No Brasil, embora existam poucos estudos sobre o assunto, pesquisa realizada no município de São Paulo por Slhessarenko e colaboradores (1996) mostrou que $46 \%$ dos gatos domésticos testados pelo IFA foram positivos para anticorpos contra B. henselae. Loureiro (1999), utilizando IFA, identificou, respectivamente, $16 \%$ e $26,5 \%$ de positividade nas amostras analisadas de gatos domésticos de São Paulo para anticorpos de $B$. henselae e de $B$. quintana. Desconhecemos a existência de estudos de prevalência através da PCR em gatos domésticos, até o momento, no Brasil.

Constituiu objetivo deste estudo a avaliação da frequência de Bartonella spp. em gatos domésticos domiciliados do Município de Vassouras (RJ), através da PCR e sorologia, comparando-se os achados e considerando o crescimento da população felina e a sua importância na epidemiologia das bartoneloses.

\section{Material e métodos}

\section{Amostras}

Após consentimento dos proprietários e aprovação no Comitê de Ética de Pesquisa com Animais (CEPA), amostras de sangue de 37 (100\%) gatos domésticos de um abrigo do município de Vassouras (RJ) foram analisadas neste estudo preliminar. Todos os animais eram adultos, 18 machos e 19 fêmeas, sem raça definida, clinicamente sadios e não apresentavam ectoparasitas, embora tivessem histórico anterior de ectoparasitismo. Os animais não tinham acesso ao exterior do abrigo. Após contenção mecânica, 3,0 mL de sangue foram coletados assepticamente por venipunção jugular ou cefálica de cada animal. Dois mililitros de sangue foram acondicionados em tubo estéril contendo anticoagulante EDTA e um $\mathrm{mL}$ em tubo estéril sem anticoagulante. As amostras de soro e sangue total foram armazenadas $\mathrm{a}-20^{\circ} \mathrm{C}$ até o processamento.

\section{Análise molecular - PCR}

A análise molecular foi realizada no Laboratório de Hantaviroses e Rickettsioses do Instituto Oswaldo Cruz (LHR), seguindo os protocolos previamente estabelecidos e validados (Anderson et al., 1994; Avidor et al., 1997; Lamas et al., 2007), descritos brevemente a seguir. O DNA foi obtido a partir de $0,1 \mathrm{~mL}$ de sangue com EDTA usando um kit comercial (GFX Genomic blood DNA purification kit, GE Healthcare, Piscataway, NJ, EUA), de acordo com o protocolo descrito pelo fabricante. O DNA extraído foi amplificado com o par de primers CAT-1 (GATTCAATTGGTTTGAAGGAGGCT) e CAT-2 (TCACATCACCAGGACGTATTC), para amplificação de um fragmento de 414 pares de base da proteína de choque térmico de 60-kDa para $B$. henselae e $B$. quintana. A mistura para a PCR (volume total de $25 \mu \mathrm{L}$ ) foi composta por $5 \mu \mathrm{L}$ de DNA, 2,5 $\mu \mathrm{L}$ de tampão de PCR 10X, 0,8 $\mu \mathrm{M}$ de cada primer (IDT/ Prodimol, Belo Horizonte, MG), $200 \mu \mathrm{M}$ de cada nucleotídeo, e 0,65 U de Taq polymerase (Platinum Taq, Invitrogen, Carlsbad, CA, EUA). O termociclador automático 
2400 (Applied Biosystem, Foster City, CA, EUA) foi programado para desnaturação de $95^{\circ} \mathrm{C}$ por 5 minutos (min), seguida por 40 ciclos de $94^{\circ} \mathrm{C}$ por $1 \mathrm{~min}$, anelamento a $50^{\circ} \mathrm{C}$ por $1 \mathrm{~min}$, e extensão a $72^{\circ} \mathrm{C}$ por $1 \mathrm{~min}$. A amplificação foi completa na temperatura de $72^{\circ} \mathrm{C}$ por 7 min para permitir a total extensão dos produtos da PCR. Cada PCR incluiu DNA extraído de $B$. henselae como controle positivo e água nuclease free (Promega, Madison, WI. EUA) como controle negativo para verificar a ausência de contaminação pelo DNA. Para confirmar a amplificação, os produtos obtidos foram separados através de eletroforese em gel de agarose a $1 \%$ corado com $3 \mu \mathrm{L}$ de solução de brometo de etídio $(10 \mathrm{mg} / \mathrm{ml}$ para $100 \mathrm{ml}$ de gel). A eletroforese foi realizada em tampão TBE $1 \mathrm{X}$ a $5 \mathrm{~V} / \mathrm{cm}$ e os produtos de amplificação foram visualizados em gel, sob luz ultravioleta, utilizando sistema de fotodocumentação Universal Hood II, programa Quantity one 4.6 (BioRad, Segrate, Itália). Para permitir o cálculo do tamanho dos fragmentos foi utilizado o padrão de tamanho de DNA 100 pb (invitrogen, Carlsbad, CA, EUA) em cada gel. A PCR foi considerada positiva a partir da identificação de uma banda de 414 pares de base.

\section{Análise sorológica - IFA}

A análise sorológica foi realizada no LHR, utilizando IFA com antígeno B.henselae (Bion ${ }^{\mathrm{TM}}$, USA), seguindo o protocolo do referido laboratório de acordo com as recomendações do fabricante, com um ponto de corte para considerar a amostra reagente ou não reagente de 1:64. Uma única amostra foi analisada, uma vez que o objetivo foi analisar exposição ao micro-organismo. Amostras apresentando reações fortes, após uma triagem de 1:64, foram progressivamente diluídas a $1: 64,1: 128,1: 256,1: 512$, e 1:1024 em tampão salina fosfato até seu "end-point". A intensidade da fluorescência específica foi avaliada subjetivamente (com escores de $1 \mathrm{a}$ 4) e o título de anticorpos foi definido pela principal diluição com escore 2.

\section{Análise estatística}

Os dados foram submetidos a análise descritiva, onde foram calculados os percentuais de positividades obtidos por cada método de diagnóstico. O índice Kappa (k) de concordância foi aferido entre as técnicas de PCR e IFA.

\section{Resultados e discussão}

Das 37 (100\%) amostras analisadas, 36 (97,3\%) foram positivas na PCR (Figura 1). Destas 36 (100\%) amostras positivas pela PCR, nove (25\%) foram positivas também no IFA, 27 (75\%) não apresentaram anticorpos anti-Bartonella e apenas uma amostra foi concomitantemente negativa na PCR e na IFA.

As frequências de amostras $P C R$ positivas encontradas neste estudo foram elevadas em relação às frequências encontradas para Bartonella spp. em felinos domésticos utilizando-se a mesma técnica diagnóstica em outras regiões do mundo. A altíssima frequência encontrada $(97,3 \%)$ provavelmente é resultante do fato de os animais estarem confinados no mesmo recinto / abrigo. Assim, a proximidade faz aumentar o risco de contágio, seja direto (através da inoculação do agente por arranhaduras ou mordeduras entre

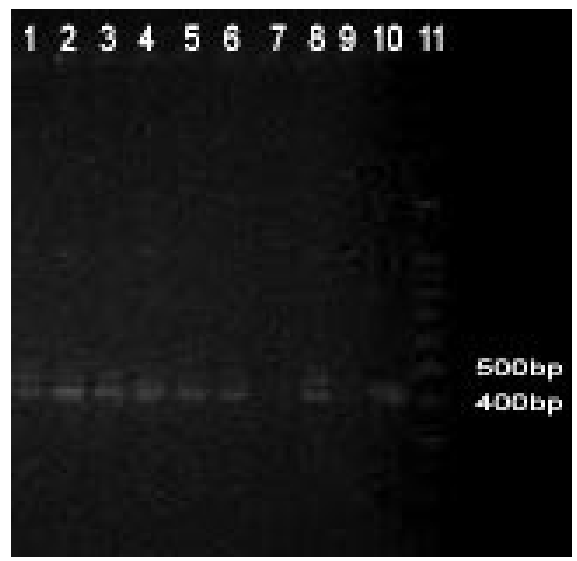

Figura 1: Gel de agarose a 1,5\% corado por brometo de etídio, de amostras de gatos domésticos do estado do Rio de Janeiro - Brasil, utilizando pimer Cat 1 e Cat 2 para a detecção da proteína de choque térmico de $60 \mathrm{kDa}$ para $B$. henselae e $B$. quintana com banda esperada de 414 pares de base (bp). Poços de 1 a 6 e 8 amostras positivas; poço 7 amostra negativa; poço 9 controle negativo e poço 10 controle positivo para Bartonella spp. Poço 11 padrão de peso molecular (100 bp Invitrogen).

os animais) ou indireto (através de vetores artrópodes) (AlMajali et al., 2004; CASE et al., 2006). Entretanto, esta alta frequência para Bartonella spp. em animais de abrigos não foi encontrada por Bergmans et al. (1997) em felinos na Holanda e isto foi relacionado com o clima temperado do país, que torna difícil a propagação do vetor. Embora os animais estivessem utilizando ectoparasiticida no momento da coleta, todos tinham histórico anterior de infestação por pulgas, o que aumentaria o risco de infecção.

A frequência de $25 \%$ de sororreagentes para Bartonella spp. encontrada em gatos domésticos neste estudo é semelhante à descrita por Loureiro (1999) em felinos domésticos de São Paulo (16\% para Bartonella henselae e $26,5 \%$ para $B$. quintana). Al-Majali et al (2004) encontraram valores de soroprevalência próximos aos encontrados neste estudo para B. henselae em felinos domésticos da Jordânia (32\%), assim como Luria et al. (2004) de 33,6\% em felinos domésticos da Flórida (EUA) e Case et al. (2006), de 14,7\% em felinos domésticos da Califórnia.

Entretanto, a frequência observada neste estudo é inferior à prevalência de $46 \%$ encontrada por Slhessarenko et al., (1996) também em felinos domésticos de São Paulo e à prevalência encontrada por outros autores referenciados em felinos domésticos sadios, como $85,6 \%$ no Chile (Férres et al., 2005), 71,4\% na Espanha (Solano-Gallego et al., 2006) e $70,1 \%$ nos EUA (Pearce et al., 2006).

A baixa concordância entre os resultados obtidos com a IFA e com a PCR neste estudo $(k=0,0177)$ mostra a baixa eficiência de um método em relação ao outro. Apesar de amplamente utilizada como ferramenta diagnóstica, a IFA pode ser negativa em casos de infecção recente na qual não seja possível a detecção de anticorpos, por tempo insuficiente para indução da síntese destes (Lamas et al., 2008b), o que pode ter ocorrido com os animais avaliados. Apesar de pouco provável e de não ter sido objetivo deste estudo, não se pode descartar a possibilidade também de uma imunossupressão com consequente deficiência na síntese de anticorpos contra a bactéria, conforme sugerido por Molia et al. (2004) e Hackett et al. (2006). 
Estudos realizados por autores nos Estados Unidos e África do Sul reforçam os resultados obtidos (Pretorius et al., 1999; Hackett et al., 2006). Considerando que a amplificação do DNA de Bartonella spp. do sangue de felino através de PCR prova que este animal estava infectado pelo micro-organismo no momento da coleta (Hackett et al., 2006), Pretorius et al. (1999) descreveram em seu estudo com felinos domésticos da África do Sul que, enquanto nenhum dos animais apresentou anticorpos para $B$. henselae, uma sequencia idêntica à $B$. henselae (Houston-1) foi identificada em um destes animais. Posteriormente, Molia et al. (2004) também reportaram ausência de anticorpos para Bartonella spp. em três felídeos selvagens com bacteremia confirmada por cultura e PCR. Os autores relataram como possíveis razões para a ausência de resposta sorológica a imunossupressão, especialmente pelo vírus da imunodeficiência felina, a coleta do soro em estágios iniciais de infecção ou a ausência de reação cruzada entre as espécies. Hackett et al (2006) afirmaram que resultados sorológicos falso-negativos para Bartonella spp. podem ocorrer, principalmente no início da infecção.

\section{Agradecimentos}

À FAPERJ e CAPES, pelo auxílio financeiro, e à Maria Angélica Monteiro de Mello Mares-Guia (LHR - FIOCRUZ) pelo auxílio na edição da fotografia.

\section{Referências}

AL-MAJALI, A.M. Seroprevalence of and risk factors for Bartonella henselae and Bartonella quintana infections among pet cats in Jordan. Prev. Vet. Med., v. 64, p. 63-71, 2004.

ANDERSON, B.; SIMS, K.; REGNERY, R.; ROBINSON, L.; SCHMIDT, M.J.; GORAL, S.; HAGER, C; EDWARDS, K. Detection of Rochalimaea henselae DNA in Specimens from Cat Scratch Disease Patients by PCR. J. Clin. Microbiol., v. 32, n. 4, p. 942-948, 1994.

AVIDOR, B.; KLETTER, Y.; ABULAFIA, S.; GOLAN, Y.; EPHROS, M.; GILADI, M. Molecular Diagnosis of Cat Scratch Disease: a Two-Step Approach. J. Clin. Microbiol., v. 35, n. 8, p. 1924-1930, 1997.

BERGMANS, A.M.; de JONG, C.M.; van AMEROGEN, G.; SCHOT, C.S.; SCHOLUS, L.M. Prevalence of Bartonella species in domestic cats in The Netherlands. J. Clin. Microbiol., v. 35, n. 9, p. 2107-2113, 1997.

BREITSCHWERDT, E.B.; KORDICK, D.L. Bartonella infection in animals: carriership, reservoir potential, pathogenicity, and zoonotic potential for human infection. Clin. Microbiol. Reviews, v. 13, n. 3, p. 428-438, 2000.

BREITSHWERDT, E.B.; MAGGI, R.G.; SIGMON, B.; NICHOLSON, W.L. Isolation of Bartonella quintana from a human and a cat following putative bite transmission. J. Clin. Microbiol., v. 45, n. 1, p. 270-272, 2007.

BREITSCHWERDT EB. Feline bartonellosis and cat scratch disease. Vet. Immun. Immunopat., v. 15, n. 123 (1-2), p.167-171, 2008.

BRENNER, D.J.; O'CONNOR, S.; WINKLER, H.H.; STEIGERWALT, A.G. Proposals to unify the genera Bartonella and Rochalimaea, with de-scriptions of Bartonella quintana comb. nov., Bartonella vinsonii comb.nov. and to remove the family Bartonellaceae from the or-der Rickettsiales. Int. J. Syst. Bacteriol., v. 43, p. 777-786, 1993.

CASE, J.B.; CHOMEL, B.B.; NICHOLSON, W.; FOLEY, J.E. Serological survey of vector-borne zoonotic pathogens in pet cats and cats from animal shelters and feral colonies. J. Fel. Med. Surg., v. 8, n. 2, p. 111-117, 2006.
Este é o primeiro estudo no Brasil a utilizar a técnica molecular para identificar a infecção por Bartonella spp. em felinos domésticos. No entanto, maiores estudos são necessários com diferentes populações de gatos e em diferentes regiões do estado do Rio de Janeiro para, entre outros objetivos, possibilitar a identificação das espécies de Bartonella circulantes assim como as taxas de prevalência e contribuir com a vigilância desta zoonose desconhecida e subestimada no Brasil e no mundo.

\section{Conclusão}

Os resultados apresentados confirmam a elevada frequência de infecção por Bartonella spp. em felinos domésticos mantidos em abrigo no município de Vassouras/RJ. Devido à baixa associação entre os resultados dos métodos diagnósticos utilizados, recomendamos o uso da PCR em vez da sorologia para diagnóstico da exposição/infecção por Bartonella spp.
CHOMEL, B.B.; BOULOUIS, H.J.; MARUYAMA, S.; BREITSHWERDT, E.B. Bartonella spp. in pets and effect on human health. Emerg. Infect. Dis., v. 12, n. 3, p. 389-394, 2006.

COSTA, P.S.G.;BRIGATTE, M.E. \& GRECO, D.B. Antibodies to Ricketsia rickettsii, Rickettsia typhi, Coxiella brunetti, Bartonella henselae, Bartonella quintana, and Ehrlichia chaffeensis among healthy population in Minas Gerais, Brazil. Mem. Inst. Oswaldo Cruz, v. 100 n. 8, p. 853-859, 2005.

DINIZ, P.P.; MAGGI, R.G.; SCHWARTZ, D.S.; CADENAS, M.B.; BRADLEY, J.M.; HE-GARTY, B.; BREITSCHWERDT, E.B. Canine bartonellosis: serologi-cal and molecular prevalence in Brazil and evidence of co-infection with Bartonella henselae and Bartonella vinsonii subsp. berkhoffii. Vet. Res., v. 38, p. 697-710, 2007.

FÉRRES, M.G.; ABARCA, K.V.; GODOY, P.M.; GARCIA, P.C.; PALAVECINO, E.R.; MENDEZ, G.R.; VÁLDES, A.O.; ERNST, S.M.; THIBAUT, J.L.; KOBERG, J.; CHANQUEO, L.C.; VIAL, P.A.C.; Presencia de Bartonella henselae en gatos: cuantificación del reservorio natural y riesgo de esposición humana de esta zoonosis en Chile. Rev. Méd. Chile, v. 133, p. 1465-1471, 2005.

FENOLLAR, F.; RAOULT, D. Molecular genetic methods for the diagnosis of fastidious microorganisms. A.P.M.I.S., v. 112, p. 785807,2004

HACKETT, T.B.; JENSEN, W.A.; LEHMAN, T.L.; HOHENHAUS, A.E.; CRAWFORD, P.C.; GIGER, U.; LAPPIN, M.R. Prevalence of DNA of Mycoplasma haemofelis, 'Candidatus Mycoplasma haemominutum; Anaplasma phagocytophilum, and species of Bartonella, Neorickettsia and Ehrlichia in cats used as blood donors in the United States. J. Am. Med. Assoc, v. 229, n. 5, p. 700-705, 2006.

KORDICK, D.L.;BROWN, T.T.; SHIN, K.;BREITSCHWERDT, E. B. Clinical and pathologic evaluation of chronic Bartonella henselae or Bartonella clarridgeiae infection in cats. J. Clin. Microbiol., v. 37, n. 5, p. 15361547, 1999.

LAMAS C.; FAVACHO A.; ROZENTAL T.; BÓIA M.N.; RAMOS R.G.; SANTOS M.S.; FERRAIUOLI G.I.; WEKSLER C.; LEMOS E.R.S. Bartonella native valve endocarditis: the first brazilian case alive and well. Braz. J. Infect. Dis., v. 11, n.6, p.591-594, 2007. 
LAMAS, C.; CURI, A.; BÓIA, M.N.; LEMOS, E.R.S. Human bartonellosis: seroepidemiological and clinical features with an emphasis on data from Brazil - A Review. Mem. Inst. Oswaldo Cruz, v. 103, n. 3, p. 221235, 2008a.

LAMAS C.; FAVACHO A.; RAMOS R.G.; SANTOSM.S.; KIRSTEN, A.H.; GUTERRES, A.; BARREIRA, J.D.; LEMOS E.R.S. Characterization of Rickettsia rickettsi in a case of fatal spotted fever in the city of Rio de Janeiro. Braz. J. Infect. Dis., v. 12, n. 2, p. 149-151, 2008b.

LAPPIN, M.R.; GRIFFIN, B.;BRUNT, J.; RILEY, A.; BRUNEY, D.; HAWLEY, J.; BREWER, M.M.; JENSEN, W.A. Prevalence of Bartonella species, haemoplasma species, Ehrlichia species, Anaplasma phagocytophilum, and Neorickettsia risticci DNA in the blood of cats and their fleas in the United States. J. Fel. Med. Surg., v. 8, n. 2, p. 8590, 2006.

LOUREIRO, V.S. Pesquisa de anticorpos anti-Bartonella henselae e anti-Bartonella quintana em felinos domiciliados na cidade de São Paulo, através da técnica de imunofluorescência indireta. 1999. 69 f. Dissertação (mestrado) - Faculdade de Medicina Veterinária e Zootecnia - Universidade de São Paulo, 1999.

LURIA, B.J.; LEVY, J.K.; LAPPIN, M.R.; BREITSCHWERDT, E.B.; LEGENDRE, A.M.; HERNANDEZ, J.A.; GORMAN, S.P.; LEE, I.T. Prevalence of infectious diseases in feral cats in northern Florida. $J$. Fel. Med. Surg., v. 6, p. 287-296, 2004.

MOGOLLON-PASAPERA, E.; OTVOS JR, L.; GIORDANO, A.; CASSONE, M. Bartonella: emerging pathogen or emerging awareness? Int. J. Inf. Dis., v. 13, p. 3-8, 2009.
MOLIA, S.; CHOMEL, B.B.; KASTEN, R.W.; LEUTENEGGER, C.M.; STEELE, B.R.; MARKER, L.; MARTENSON, J.S.; KEET, D.F.; BENGIS, R.G.; PETERSON, R.P.; MUNSON, L. O'BRIEN, S.J. Prevalence of Bartonella infection in wild African lions (Panthera leo) and cheetahs (Acynonyx jubatus). Vet. Microbiol., v. 10, p. 31-41, 2004.

PRETORIUS, A.M.; KELLY, P.J.; BIRTLES, R.J.; RAOULT, D. Isolation of Bartonella henselae from a serologically negative cat in Bloemfontein, South Africa. J.S. Afr. Vet. Assoc., v. 70, n. 4, p.154-155, 1999.

SLHESSARENKO, N.; CAMARGO, M.C.G.O.; DÀURIA, S.R.N. Soroprevalência de Bartonella henselae em gatos do município de São Paulo. Rev. Soc. Bras. Med. Tropic., v. 29; p.104,1996.

SOLANO-GALLEGO, L.; HEGARTY, B.; ESPADA, Y.; LIULL, J.; BREITSCHWERDT, E. Serological and molecular evidence of exposure to arthropod-borne organisms in cats from northeastern Spain. Vet. Mibrobiol, v. 16, 2006.

WIKSWO, M.E.; HU, R.; METZGER, M.E.; EREMEEVA, M.E. Detection of Rickettsia rickettsii and Bartonella henselae in Rhipicephalus sanguineus ticks from California. J. Med. Entomol., v. 11, n. 1, p. 158162, 2007.

ZANUTTO, M.S.; MAMIZUKA, E.M.; RAIZ-JÚNIOR, R.; LIMA, T.M.; DIOGO, C.L.; OKAY, T.S.; HAGIWARA, M.K. Experimental infection and horizontal transmission of Bartonella henselae in domestic cats. Rev. Inst. Med. Trop. S. Paulo, v. 43, n. 5, p. 257-261, 2001. 